\title{
Existential attitudes as predictors of burnout in Polish nurses employed in rural primary healthcare settings
}

\author{
Anna Mazur ${ }^{1, A-F}$, Magdalena Czarkowska ${ }^{1, C-E}$, Anna Goś ${ }^{2, A, C-D, F}$, Ewa Humeniuk $k^{3, A, E-F}$ \\ 1 Institute of Rural Health in Lublin, Poland \\ ${ }^{2}$ Department of Foreign Languages, I Faculty of Medicine with Dentistry Division, Medical University of Lublin, Poland \\ ${ }^{3}$ Department of Pathology and Rehabilitation of Speech, Faculty of Health Sciences, Medical University of Lublin, Poland \\ A - Research concept and design, B - Collection and/or assembly of data, C - Data analysis and interpretation, \\ $D$ - Writing the article, E - Critical revision of the article, F - Final approval of article
} Mazur A, Czarkowska M, Goś A, Humeniuk E. Existential attitudes as predictors of burnout in Polish nurses employed in rural primary
healthcare settings. Ann Agric Environ Med. 2018; 25(3): 552-558. doi: $10.26444 /$ aaem/85650

\begin{abstract}
Introduction. Existential attitudes distinguished by G. Reker express the meaning of life and affect the way individuals perceive themselves, the reality as well as their ability to cope with challenges. Thus, it can be assumed that life attitudes also determine burnout understood as a syndrome of psychological symptoms that occur in professionally active people due to chronic occupational stress.

Objective. The aim of the study is to examine which existential attitudes determine burnout in nurses employed in rural primary healthcare settings in Poland

Material and methods. The study sample comprised 120 nurses employed in rural primary healthcare settings in Poland. The Life Attitude Profile - Revised (LAP-R) adapted by R. Klamut and The Link Burnout Questionnaire (LBQ) adapted by A. Jaworowska were used in the research.

Results. The stronger the belief of the surveyed nurses concerning life goals they possess and the more internally coherent they are, the lower psychophysical exhaustion they experience. Whereas, psychophysical exhaustion rises with an increase in the need for introducing changes in life. Relationship deterioration and disillusion decrease with the level of engagement in seeking new goals in life. The sense of professional ineffectiveness drops if the belief of the nurses that they possess life goals gets stronger. Moreover, the stronger the meaning of life becomes, the stronger the professional ineffectiveness of the nurses is.

Conclusions. The analyses performed proved that some existential attitudes are predictors of burnout in nurses employed in rural areas. The research results can be applied in the development of prevention and aid programs to enhance the quality of nurses' personal and professional performance.
\end{abstract}

Key words

existential psychology, burnout, nurses

\section{INTRODUCTION}

According to existential psychology, a human being is an active, free and intentional subject that seeks to attain their goals and relate to themselves, their life experiences and the surrounding world. [1-2]. The sign of the subject's relation to their thoughts, emotions and behaviours is experiencing meaning of life, namely the sense of understanding the world, individual's role in it and the belief that their existence is valuable [3]. In the context of the aforementioned meaning of life, Reker [4] has distinguished basic existential attitudes namely life purpose, internal coherence, death acceptance, existential vacuum, life control and goal seeking. The attitude of life purpose involves being focused on the future, having life goals and the knowledge of what is essential in life. Internal coherence is responsible for the level of an individual's integrity, their ability to understand themselves and the surrounding reality. Life control represents the conviction that one has an influence on their life and is likely

Address for correspondence: Anna Mazur, Institute of Rural Health in Lublin, Poland, Jaczewskiego 2, 20-090 Lublin, Poland

e-mail: annamazur10@o2.pl

Received: 16.08.2017; accepted: 22.02.2018; first published:08.03.2018 to take responsibility for it. Death acceptance represents understanding and accepting death as an inevitable life event. Existential vacuum is characterised by the feeling of depression, indifference and lack of meaning in life. Whereas, goal seeking is manifested by the will to undertake new challenges and strive for changes in life [5].

The aforementioned attitudes are predictors of man's quality of existence, their perception of themselves and the surrounding reality as well as the ability to cope with the challenges that they face both in personal and professional life [6]. Thus, it can be assumed that life attitudes determine the incidence of professional burnout.

Burnout is a widely spread phenomenon that affects representatives of various professions but the ones whose jobs involve helping others are particularly vulnerable to it. Professionals particularly prone to burnout include among others nurses who experience stress at work due to significant burdens and the need to provide patients with help [7-9]. Professional burnout is defined as a syndrome of psychological symptoms that occur in professionally active people due to experiencing chronic stress resulting from the lack of balance between personal resources and demands of the environment [10]. The symptoms of burnout include: 
psychophysical exhaustion, relationship deterioration, sense of professional ineffectiveness and disillusion [11]. Psychophysical exhaustion is manifested by a lowered level of individual's psychophysical resources, the feeling of fatigue and tension. Relationship deterioration refers to the quality of relationship with patients or clients which is manifested by instrumental attitude, indifference to their needs and even hostility. The sense of professional ineffectiveness is concerned with perceiving ones work as ineffective and futile, whereas disillusion results from the conviction that an individual's professional activity differs significantly from their personal expectations, values and does not present perspectives for development [12].

The issue of burnout in nurses has been discussed in plentiful empirical research studies. The study by Zhang, Loerbroks and $\mathrm{Li}$ verifies whether burnout in nurses is connected with the perceived quality of life. In the course of the longitudinal research, which comprised 305 nurses with cardiovascular diseases, the research group was divided into three subgroups - group one - nurses presenting a low level of burnout, group two - the nurses with an average level of burnout and group three - the nurses with a high level of burnout. The regression analyses performed proved that both physical fitness and mental functioning of the nurses is lower by 2.53 points and 3.02 points respectively, $\mathrm{p}<0.05$ in the nurses who presented a high level of burnout compared to the group of nurses with a low level of burnout. On the basis of the data collected, the researchers also assumed that the quality of life decreased considerably in the nurses with diagnosed cardiovascular diseases one year after burnout syndrome occurred [13].

Research of considerable interest conducted on the population of nurses employed in paediatric hospitals who worked with adolescents suffering from chronic pain, was performed by Rodrigues et al. The results obtained in the course of the research indicated that burnout in the researched group is related to the negative beliefs on chronic pain, barriers in utilizing strategies of pain management, fear of losing sympathy as well as expressing negative opinions on the hospital environment [14].

Having analysed the most recent empirical research on burnout in nurses, it is worth mentioning the research by De la Fuente-Solan et al. who focused on determining whether personality, fear and depression are linked to burnout in nurses employed in oncology wards. On the basis of the statistical analyses performed, it was stated that emotional exhaustion and depersonalization are directly proportionally linked to neuroticism as well as negatively related to agreeability, conscientiousness, extraversion and openness to new experiences. Whereas, personal accomplishment is indirectly proportionally related to neuroticism, conscientiousness, extraversion and openness to new experiences. Moreover, emotional exhaustion and depersonalization positively coexist with fear and depression and personal accomplishment is negatively connected with fear and depression [15].

According to the contemporary research, it should be noted that the issue of burnout in nurses seems to be still open and implies the need for further research on intramental conditioning of the syndrome. Distinguishing the risk and protective factors can be used for developing effective strategies aimed at prevention of burnout in nurses, which will directly improve the quality of personal and professional performance of nurses and thus affect the quality of patient care.

\section{OBJECTIVE}

The aim of the research is to determine which existential attitudes are predictors of burnout in nurses employed in rural primary healthcare settings in Poland.

\section{MATERIAL AND METHOD}

The researched sample was selected intentionally and comprised 120 nurses employed in rural primary healthcare centres in eastern Poland (the Lublin region).

The research inclusion criteria were: having given an informed consent to participate in the research, sex (only females were researched), education (higher education), age (middle-aged participants), place of residence (primary healthcare settings) and seniority (from 15 to 20 years of professional experience).

Detailed sociodemographic characteristics of the researched group is depicted in Table 1.

Table 1. Sociodemographic characteristic of the researched

Quantitative variables

\begin{tabular}{lcc}
\hline & $M$ & $S D$ \\
\hline Age & 44.51 & 15.09 \\
\hline Seniority & 15.37 & 8.84 \\
\hline Number of children & 1.62 & 1.10
\end{tabular}

Number of children

Qualitative variables

\begin{tabular}{lccc}
\hline \multirow{2}{*}{ Marital status } & & $N$ & $\%$ \\
\hline \multirow{2}{*}{ Education } & married & 68 & 56.7 \\
\cline { 2 - 4 } & single & 52 & 43.3 \\
\cline { 2 - 4 } & BSC & 72 & 60.0 \\
\hline
\end{tabular}

M - mean; SD - standard deviation; $N$ - the numer of researched nurses; \% - the percentage of researched nurses

The mean age of the surveyed nurses was above 44 years old $(M=44.51 ; S D=15.09)$. The mean employment of the surveyed was more than 15 years $(M=15.37 ; S D=8.84)$. Married women $(N=68 ; 56.7 \%)$ who dwelled in rural areas $(N=120 ; 100.0 \%)$ were dominant. The researched averagely had two children $(M=1.62 ; S D=1.10)$. Over half of them graduated from the Bachelor's degree programme $(N=72$; $60.0 \%$ ) and the remaining participants graduated from the Master's degree programme $(N=48 ; 40.0 \%)$ in nursing. The researched nurses work in a day two-shift system excluding Saturdays and Sundays and they do not work nights or on public holidays.

The research tools included The Life Attitude Profile Revised (LAP-R) adapted by R. Klamut [3] and The Link Burnout Questionnaire (LBQ) adapted by A. Jaworowska [15].

The Life Attitude Profile-Revised (the LAP-R) is used to measure the notion of meaning of life and the level of motivation to make one's life meaningful and formulate goals. The research tool consists of six basic scales that refer to different life attitudes which include: Life purpose, Internal 
coherence, Life control, Death acceptance, Existential vacuum and Goal seeking. The instrument consists of 48 items which are rated on a 7-point Likert scale. The questionnaire has sten norms which facilitates determining the intensity of existential attitudes. The higher the score obtained, the greater the intensity of the given dimension. The scores from one to three stens are of low intensity. The scores that range from four to six stens indicate an average intensity of the dimension, and the scores from seven to ten stens represent high intensity of the dimension. The Polish version of the tool is characterized by satisfactory validity and reliability. Alfa Cronbacha for separate scales ranges from 0.70 to 0.87 . The questionnaire can be applied for individual diagnosis and scientific research. The scores that range from ten to seven show high intensity of the measured attitude. Scores that comprise between six and four prove an average level of a given attitude, whereas scores of three to one inform of low intensity of the attitude [3].

The Link Burnout Questionnaire (the LBQ) is designed to diagnose the level of professional burnout in people working in social professions which involve direct interaction with other people. The tool comprises four scales that enable measurement of different aspects of burnout which are as follows Psychophysical exhaustion, Relationship deterioration, Professional ineffectiveness and Disillusion [12]. The instrument consists of 24 items rated on a sixpoint Likert scale. Alfa Cronbacha for separate scales ranges from 0.66 to 0.85 . Statistical analyses performed confirmed psychometric properties of the instrument which can be utilised for individual diagnosis and research. Raw results in the scales of the questionnaire are subject to calculation into sten norms which enables relating the results obtained to the normalization sample. The higher the score, the greater the intensity of the given scale. The scores of ten to eight are typical of a high level of burnout. The scores that range from seven to four are representative of an average level of burnout and may suggest possible problems in the diagnosed area. The scores that rank from three to one indicate the lack of symptoms of burnout $[12,16]$.

The survey was voluntary, individual and anonymous. The participants had been informed of the aim and course of the research and agreed to participate in it. The participants completed the tests in the presence of a psychologist responsible for conducting the research. Statistical calculations were performed by means of the IBM SPSS 21 software. Characteristics of the researched sample were based on the calculation of the percentage distribution of the qualitative variables frequency and descriptive statistics of quantitative variables. The intensity of the dimensions of existential attitudes as well as the symptoms of burnout were given on the basis of the mean value and standard deviation. Distribution of the discussed parameters was verified on the basis of the Kolmogorov-Smirnov test. The predictive analytics was conducted using stepwise regression. The level of statistical significance was assumed at $p<0.05$.

\section{RESULTS}

The first stage of the analyses involved estimation of the intensity of the dimensions of existential attitudes and components of burnout in the researched nurses. The dimensions of existential attitudes maintained on the moderate level which, in turn, indicated that the researched women present averagely intensified meaning of life. They focus on the future to a moderate extent which affects their life purposes (life purpose: $M=6.00 ; S D=2.06$ ). Similarly, the researched nurses are internally coherent and convinced that they understand themselves and the surrounding reality (internal coherence: $M=5.86 ; S D=2.04$ ). Furthermore, the nurses may have some doubts about their influence on their lives and may not always be ready to take responsibility for their decisions (life control: $M=5.55 ; S D=1.78$ ). Accepting death as an inevitable life event can also be found challenging for them (death acceptance: $M=4.96 ; S D=2.02$ ), thus, they can present lowered mood and indifference to the surrounding reality (existential vacuum: $M=5.17 ; S D=2.22$ ), as well as moderate willingness to undertake new challenges and introduce crucial life changes (goal seeking: $M=4.82$; $S D=1.67)$.

Whereas, the analysis of the intensity of symptoms of burnout in the researched nurses indicated that burnout maintains on the lowlevel. The nurses' psychosocial exhaustion remains on the highest level, though still within the range of low results, which suggests that stress involved in their work can affect their decreased level of personal resources and result in the feeling of tension and fatigue (psychophysical exhaustion: $M=3.37 ; S D=2.53$ ). The researched nurses are convinced to a comparable degree about their professional effectiveness (professional ineffectiveness: $M=2.99$; $S D=1.64$ ). Whereas, the quality of their relationship with the patients (relationship deterioration: $M=1.38 ; S D=0.84$ ) and the belief that their work is consistent with their personal values, expectations and provides opportunities to develop maintain on a high level (disillusion: $M=1.24 ; S D=1.09$ ).

The next stage of the analysis involved determining which existential attitudes are predictors of burnout in the nurses.

Results of regression analysis for the variable psychophysical exhaustion are presented in table 2.

Table 2. Determinants of psychophysical exhaustion

\begin{tabular}{|c|c|c|c|c|c|c|c|c|}
\hline \multirow{2}{*}{ Model } & \multicolumn{3}{|c|}{ Measures of model fit } & \multicolumn{5}{|c|}{ Regression weights for predictors } \\
\hline & $R^{2}$ adjusted & $F$ & $p$ & B & $S$ & $\beta$ & $t$ & $p<$ \\
\hline \multicolumn{9}{|l|}{ Step 1} \\
\hline Aim & 0.30 & 52.09 & 0.001 & -0.11 & 0.02 & -0.55 & 7.22 & 0.001 \\
\hline \multicolumn{9}{|l|}{ Step 2} \\
\hline Aim & \multirow{2}{*}{0.52} & \multirow{2}{*}{65.92} & \multirow{2}{*}{0.001} & -0.10 & 0.01 & -0.51 & 8.05 & 0.001 \\
\hline Goal seeking & & & & 0.11 & 0.01 & 0.48 & 7.46 & 0.001 \\
\hline \multicolumn{9}{|l|}{ Step 3} \\
\hline Aim & \multirow{3}{*}{0.54} & \multirow{3}{*}{47.86} & \multirow{3}{*}{0.001} & -0.15 & 0.02 & -0.76 & 6.44 & 0.001 \\
\hline Goal seeking & & & & 0.10 & 0.01 & 0.46 & 7.40 & 0.001 \\
\hline $\begin{array}{l}\text { Internal } \\
\text { coherence }\end{array}$ & & & & 0.06 & 0.03 & 0.29 & 2.46 & 0.05 \\
\hline
\end{tabular}

$\mathrm{R}^{2}$ adjusted-adjusted multiple correlation coefficient; $F$ - analysis of variance result that tests the significance of the model fit to the data; $\mathrm{p}$ - significance level; $\mathrm{B}$ - regression weights; $\mathrm{S}$-standard error; $\beta$-standardized regression weights; $t$-statistics that determines coefficients significance

Calculations performed allowed development of a model consisting of three steps in which three predictors explaining $54 \%$ of the variance of the explanatory variable (psychophysical exhaustion) were introduced in turn. In the first step, one of the dimensions of existential attitudes - life purpose was introduced as an explanatory variable. The model turned out to fit the data and explained $30.0 \%\left(R^{2}\right.$ adjusted $\left.=0.30\right)$ of the 
variance of dependant explanatory variable, $F(1.119)=52.09$; $p<0.001$. In the second step, another dimension of existential attitudes - goal seeking was introduced to the model. It fit the data well and explained $52.0 \%\left(R^{2}\right.$ adjusted $\left.=0.52\right)$ of the explanatory variable, $F(2.119)=65.92 ; p<0.001$. In the third step, another dimension of existential attitudes - internal coherence was introduced into the model. It also turned out to fit the data and explained $54.0 \%\left(R^{2}\right.$ adjusted $\left.=0.54\right)$ of the variance of dependant variable, $F(3.119)=47.86 ; p<0.001$. The model developed reveals that significant predictors of psychophysical exhaustion include goal, $\beta=-0.76 ; p<0.001$, goal seeking, $\beta=0.46 ; p<0.001$, as well as internal consistency, $\beta=-0.29 ; p<0.01$. Dependency between the introduced predictors and dependant variable is very high and negative in the first case, average and positive in the seconds case, as well as weak and negative in the third case. The results imply that the stronger the nurse's belief concerning what is essential in life is and the more integrated an individual is, the lower the psychophysical exhaustion is. Whereas, psychophysical exhaustion rises in the surveyed nurses with an increase in the need for introducing changes in life.

The model of regression analysis explaining relationship deterioration is depicted in table 3.

Table 3. Determinants of relationship deterioration

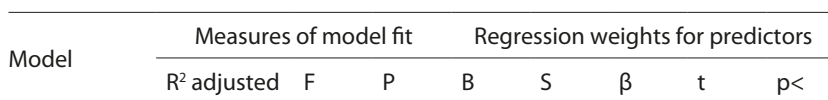

Step 1

\begin{tabular}{lllllllll}
\hline Aim & 0.24 & 39.16 & 0.001 & -0.14 & 0.02 & -0.50 & 6.26 & 0.001
\end{tabular}

Step 2

\begin{tabular}{lllllllll}
\hline Aim & & & & -0.13 & 0.02 & -0.48 & 6.15 & 0.001 \\
\cline { 4 - 7 } Goal seeking & 0.27 & 23.01 & 0.001 & 0.06 & 0.02 & 0.18 & 2.32 & 0.05
\end{tabular}

$\mathrm{R}^{2}$ adjusted-adjusted multiple correlation coefficient; $\mathrm{F}$ - analysis of variance result that tests the significance of the model fit to the data; $\mathrm{p}$ - significance level; $\mathrm{B}$ - regression weights; $\mathrm{S}$-standard error; $\beta$-standardized regression weights; $t$ - statistics that determines coefficients significance

Calculations conducted in the course of the research resulted in a model consisting of two steps in which two predictors explaining $27.0 \%$ of the variance of variable relationship deterioration were introduced in turn. In the first step, one of the subscales of existential attitudes - life purpose was introduced to the model as a predictor. The model turned out to fit the data well and explained $24.0 \%$ $\left(R^{2}\right.$ adjusted $\left.=0.24\right)$ of variance of explanatory variable, $F(1.119)=39.16 ; p<0.001$. In the second step, another dimension of existential attitudes - goal seeking was introduced into the model as an explanatory variable. It also fit the data well and explained $27.0 \%$ ( $R$ adjusted $=0.27$ ) of the variance of the dependant variable. $F(2.119)=23.01 ; p<0.001$. The developed model indicates that life purpose $\beta=-0.48 ; p<0.001$ and goal seeking $\beta=0.18 ; p<0.05$ are significant predictors of the scale relationship deterioration. Relation between the introduced predictors and the dependant variable is average and inversely proportional in the case of life purpose as well as weak and positive in the case of goal seeking. The data obtained show that the higher the belief concerning life purpose one has, the stronger the relationship deterioration. Whereas, the more nurses strive for new challenges in their lives, the more instrumentally they treat patients and the more indifferent they become to their needs.
Table 4. Determinants of the sense of professional ineffectiveness

\begin{tabular}{|c|c|c|c|c|c|c|c|c|}
\hline \multirow{2}{*}{ Model } & \multicolumn{3}{|c|}{ Measures of model fit } & \multicolumn{5}{|c|}{ Regression weights for predictors } \\
\hline & $\mathrm{R}^{2}$ adjusted & $\mathrm{F}$ & $\mathrm{p}$ & B & $S$ & $\beta$ & $\mathrm{t}$ & $\mathrm{p}<$ \\
\hline \multicolumn{9}{|l|}{ Step 1} \\
\hline Aim & 0.47 & 104.57 & 0.001 & -0.12 & 0.01 & -0.69 & 10.23 & 0.001 \\
\hline \multicolumn{9}{|l|}{ Step 2} \\
\hline Aim & & & & -0.10 & 0.01 & -0.58 & 7.77 & 0.001 \\
\hline $\begin{array}{l}\text { Existential } \\
\text { vacuum }\end{array}$ & 0.50 & 60.43 & 0.001 & 0.04 & 0.01 & 0.22 & 3.02 & 0.005 \\
\hline
\end{tabular}

$\mathrm{R}^{2}$ adjusted - adjusted multiple correlation coefficient; $\mathrm{F}$ - analysis of variance result that tests the significance of the model fit to the data; $\mathrm{p}$ - significance level; $\mathrm{B}$ - regression weights; $\mathrm{S}$-standard error; $\beta$-standardized regression weights; $t$-statistics that determines coefficients significance

Results of regression analysis for the variable - sense of professional ineffectiveness are shown in table 4.

Calculations performed in the course of the research resulted in a model consisting of two steps in which two predictors explaining $50 \%$ of the variance of variable the sense of professional ineffectiveness were introduced into the model in turn. In the first step, one of the scales of existential attitudes - life purpose was introduced into the model as a predictor. The model turned out to fit the data well and explained $47.0 \%\left(R^{2}\right.$ adjusted $\left.=0.47\right)$ of the variance of explanatory variable, $F(1.119)=104.57 ; p<0.001$. In the second step, another scale of the researched attitudes - existential vacuum was introduced into the model as an explanatory variable. The model turned out to be well suited to the data and explained $50.0 \%$ ( $R$ adjusted $=0.50)$ of variance of dependant variable, $F(2.119)=60.43 ; p<0.001$. The model developed in the course of the research indicates that life purpose, $\beta=-0.58 ; p<0.001$ and existential vacuum, $\beta=0.22$; $p<0.005$, are significant predictors of the scale - the sense of professional ineffectiveness. Relation between the predictors and dependant variable is strong and inversely proportional in the case of life purpose as well as weak and positive in the case of existential vacuum. The data obtained suggest that the higher the belief that one possesses life goals, the lower the sense of professional ineffectiveness and the higher the conviction of lack of meaning of life, the stronger the sense of professional ineffectiveness.

The model of regression analysis explaining disillusion is given in table 5 .

Table 5. Determinants of disillusion

\begin{tabular}{lccccccccc}
\hline \multirow{2}{*}{ Model } & \multicolumn{3}{c}{ Measures of model fit } & \multicolumn{6}{c}{ Regression weights for predictors } \\
\cline { 2 - 9 } & $\mathrm{R}^{2}$ adjusted & $\mathrm{F}$ & $\mathrm{p}$ & $\mathrm{B}$ & $\mathrm{S}$ & $\beta$ & $\mathrm{t}$ & $\mathrm{p}$ \\
\hline Step 1 & & & & & & & & \\
\hline Aim & 0.25 & 41.07 & 0.001 & -0.09 & 0.01 & -0.51 & 6.41 & 0.001 \\
\hline Step 2 & & & & & & & & \\
\hline Aim & 0.29 & 25.84 & 0.001 & -0.09 & 0.01 & -0.49 & 6.33 & 0.001 \\
\hline Goal seeking & & & & 0.04 & 0.02 & 0.22 & 2.85 & 0.005 \\
\hline
\end{tabular}

R2 adjusted - adjusted multiple correlation coefficient; $F$ - analysis of variance result that tests the significance of the model fit to the data; $\mathrm{p}$-significance level; $\mathrm{B}$ - regression weights; $\mathrm{S}$-standard error; $\beta$-standardized regression weights; $t$-statistics that determines coefficients significance

Calculations performed in the course of the research resulted in a model consisting of two steps in which two predictors explaining $29 \%$ of the variance of explanatory variable (disillusion) were introduced into the model in turn. In the first step, one of the dimensions of existential attitudes - life purpose was introduced into the model as an 
explanatory variable. The model turned out to fit the data well and explained $25.0 \%$ ( $R^{2}$ adjusted $\left.=0.25\right)$ of the variance of dependant variable, $F(1.119)=41.07 ; p<0.001$. In the second step, another scale of existential attitudes - goal seeking was introduced into the model. The model turned out to be well suited to the data and explained $29.0 \%\left(R^{2}\right.$ adjusted $\left.=0.29\right)$ of variance of dependant variable, $F(2.119)=25.84 ; p<0.001$. The model developed in the course of the research reveals that life purpose, $\beta=-0.49 ; p<0.001$ and goal seeking, $\beta=0.22$; $p<0.005$ are significant predictors of the scale disillusion. Relation between the introduced predictors and dependant variable is average and negative in the first case as well as weak and positive in the second case. This suggests that the stronger the belief concerning what is essential in life is, the lower disillusion becomes. Whereas, disillusion rises with an increase in the need for introducing life changes and one loses passion and enthusiasms connected with their professional activity.

\section{DISCUSSION}

The aim of the research presented was to define which existential attitudes determine burnout in nurses employed in rural primary healthcare settings in Poland.

The analyses performed proved that in the case of psychophysical exhaustion three attitudes, namely life purpose, goal seeking and internal coherence, are significant. Psychophysical exhaustion in the surveyed nurses is higher if they find determining what is the most important in life difficult. The stronger the need for introducing changes in their lives and the lower the ability to understand themselves and the surrounding world, the stronger the psychophysical exhaustion becomes. Whereas, life purpose and goal seeking turned out to determine one element of burnout, namely relationship deterioration.

The analyses conducted indicate that the greater the difficulties in setting personal goals are and the stronger the focus on new challenges in life is, the poorer the quality of nurses' relations with patients becomes. The sense of professional ineffectiveness is explained by life purpose and existential vacuum. The analyses result in the assumption that the conviction that the surveyed lack professional skills is intensified with a decrease in life goals and an increase in the sense of lack of meaning in life. Life purpose and goal seeking turned out to be predictors of disillusion. The data obtained suggest that nurses' disillusion rises with an increase in problems setting personal goals and the intensification of the need for introducing changes in life.

Dependencies between existential attitudes and burnout in nurses were verified on the basis of the correlation matrix analysis. The analysis revealed that psychosocial exhaustion and relationship deterioration coexist indirectly proportionally with life purpose, internal coherence, life control, death acceptance and directly proportionally with existential vacuum and goal seeking. Whereas, the feeling of professional ineffectiveness and disillusion are negatively related to life purpose, internal coherence, life control and are positively related to existential void and goal seeking [17].

The empirical research by Pinikahana and Happell concerning the issue of burnout in nurses depicted that $11.0 \%$ of psychiatric nurses employed in rural settings present an increased level of burnout, especially in the dimension of personal accomplishment. Furthermore, the researched nurses indicated that the dominant stressors include the workload and the feeling of being inadequately prepared for the job. In spite of the perceived shortages, considerable majority of nurses confirmed satisfaction with their job, their current professional situation, the level of obtained support as well as the opportunity to get engaged in a decision-making process [18].

A study performed in Lleida, Spain on a group of 135 general practitioners and 131 nurses investigated the association between burnout and empathy [19]. Empathy, which refers to the ability to understand the experiences and feelings of another person and to communicate this understanding to them, results in improved clinical outcomes. The data obtained proved that more empathic healthcare professionals presented lower levels of burnout. What is more, practitioners employed in rural areas have significantly lower levels of empathy than their urban counterparts. Whereas, emotional exhaustion and depersonalization scores were both lower in rural areas.

Arman et al. investigated a group of Swedish people affected by burnout syndrome which prevented them from living an active and healthy life [20]. The research lasted one year and was aimed at looking especially at the patterns of health, suffering and expressions of understanding of life in a longitudinal perspective. In Sweden, burnout 'phenomenon' has become a medical diagnosis and many people have been on sick leave for longer or shorter periods of time since the beginning of the 1990s. There were indications that people affected by burnout tended to shut themselves off from their own suffering. From having been an issue connected to working life, it has become more of a question for health care services.

Kolthoff and Hickman [21], Lee and Seomun [22] and Durkin et al. [23] have shown in their research that there is an inversely proportional connection between burnout in nurses and compassion they show to patients and themselves. However, Duarte and Pinto-Gouveia noted that negative selforiented emotions elicited by others' distress were associated with burnout and compassion fatigue [24]. Taleghani et al. observed in oncology nurses that burnout leads to lowered empathy due to depersonalization and empathy prevents burnout due to an increase in job satisfaction [25]. GandoyCrego et al. emphasize the role of endogenous factors such as personal determinants of burnout in nurses [26]. The study revealed that emotional exhaustion is correlated to sociability whereas reduced personal performance is correlated with responsibility and neuroticism. Thus, individuals high in sociability and low in neuroticism as well as less involved in personal development seem to be less prone to professional burnout. The study by Vander et al. aimed at investigating burnout in Belgian home health-care nurses proved that the strongest determinants of burnout are emotional demands the nurses experience and the level of engagement in their work [27]. Whereas, resistance resources, social support in particular, function as a factor protecting from burnout. An integrative research of burnout that included socio-demographic characteristics, job stressors and hardy personality depicted that positive aspects of personality and hardiness in nurses reduces the experience of occupational stress and acts as protection factors from burnout [28].

Some plentiful Polish studies have been devoted to the issue of burnout in nurses. Kurowska and Zuza-Witkowska 
proved that the feeling of lack personal accomplishments among nurses who deal with oncology patients is indirectly proportionally linked to their ability to take other's perspective. Whereas, emotional exhaustion and depersonalization are positively connected with the feeling of personal distress. [29]. The research by Włodarczyk and Obacz confirmed the hypothesis that inadequate perfectionism has a harmful effect on experiencing burnout by surgical nurses. The results of the hierarchical regression analysis proved that having controlled some of the demographic and professional characteristics, inadequate perfectionism turned out to be a significant factor that explained departing from emotionality, whereas, adaptive perfectionism determined greater engagement in work. Education, the number of places of employment, responsibilities at work and marital status were also the key predictive factors [30].

It is worth mentioning the empirical study by Dębska and Cepuch, which indicated that protective factors in nurses employed in primary healthcare settings included self-esteem at work, social support and the lack of excessive burden of life changes [31].

According to the authors' own research and other studies, there is the need for developing proper psycho-prophylactic measures aimed at the improvement of professional performance of nurses. The necessity for implementing such procedures is also suggested by Nowrouzi et.al who stress that interventions concerned with enhancing coping effectiveness in nurses should result in a decrease of burnout symptoms in this professional group. [32].

\section{CONCLUSIONS}

The analyses performed proved that some existential attitudes are predictors of burnout in nurses employed in rural primary healthcare settings in Poland.

The stronger the nurses' belief concerning life goals they possess and the more coherent they are, the lower the psychophysical exhaustion they experience. Whereas, psychophysical exhaustion rises with an increase in the need for introducing changes in life. Relationship deterioration and disillusion drop along with an increase in the intensity of the belief concerning life goals they have and rise with the level of engagement in striving for new challenges in life. The stronger the conviction that they possess life goals is, the lower the sense of professional ineffectiveness becomes. Moreover, the sense of professional ineffectiveness rises if the sense of lack of meaning of life intensifies.

\section{SUMMARY}

The results obtained in the research are of great cognitive significance and can be applied in the development of prevention and aid programs to enhance the quality of personal and professional performance of nurses employed in rural areas.

\section{REFERENCES}

1. Frankl VE. Homo Patiens. Warszawa Instytut Wydawniczy PAX, 1984

2. Popielski K. Człowiek - wartości - sens. Studia z psychologii egzystencji (Human - values - meaning. Studies on existential psychology). Lublin Redakcja Wyd. KUL, 1996.

3. Klamut R. Kwestionariusz Postaw Życiowych KPŻ. Podręcznik do polskiej adaptacji Kwestionariusza Life Attitude Profile-Revised (LAP-R) Gary'ego T. Rekera. (Manual to the Polish adaptation of The Life Attitudes Profile - Revised (LAP-R) by Gaty T. Reker). Warszawa Pracownia Testów Psychologicznych PTP, 2010.

4. Reker GT. Life Attitude Profile - Revised (LAP-R). Ontario Students Psychologists Press, 1992.

5. Reker GT, Peacock EJ. The Life Attitude Profile (LAP): A multidimensional instrument for assessing attitudes toward life. Can J Behav Science. 1981; 13(3): 264-273.

6. Reker GT, Wong PT. Aging as an individual process: Toward The theory of personal meaning. In: Birren JE, Bengtson VL, editors. Emergent the theories of aging. New York: Springer Publishing; 1988. p. 214-246.

7. Sęk H. Wypalenie zawodowe. Przyczyny i zapobieganie (Professional burnout. Causes and prevention). Warszawa Wydawnictwo Naukowe PWN, 2012.

8. Wilczek-Rużyczka E. Wypalenie zawodowe pracowników medycznych (Professional burnout of medical professionals). Warszawa ABC Wolters Kluwer Business, 2014.

9. Li YY, Li LP. An investigation on job burnout of medical personnel in a top three hospital. Zhonghua Lao Dong Wei Sheng Zhi Ye Bing Za Zhi. 2016; 34(5): 357-360.

10. Lewandowska A, Litwin B. Wypalenie zawodowe jako zagrożenie w pracy pielęgniarki (Professional burnout as a threat in nurse's practice). Rocz Pom AM. 2009; 55(3): 86-89.

11. Queiros C, Carlotto MS, Kaiseler M, et al. Predictors of burnout among nurses: An integrationists approach. Psicothema. 2013; 25(3): 330-335.

12. Santinello M. LBQ Kwestionariusz Wypalenia Zawodowego. Podręcznik. (LBQ The Link Burnout Questionnaire. Manual). Warszawa Pracownia Testów Psychologicznych PTP, 2014.

13. Zhang M, Loerbroks A, Li J. Job burnout predicts decline of healthrelated quality of life among employees with cardiovascular disease: A one-year follow-up study in female nurses. Gen Hosp Psychiatry. 2017; 17(50): 51-53.See comment in PubMed Commons below

14. Rodrigues NP, Cohen LL, Swartout KM, Trotochaud K, Murray E. Burnout in Nurses Working With Youth With Chronic Pain: A MixedMethods Analysis. J Pediatr Psychol. 2017. doi: 10.1093/jpepsy/jsx105. See comment in PubMed Commons below

15. De la Fuente-Solana EI, Gómez-Urquiza JL, Cañadas GR, AlbendínGarcía L, Ortega -Campos E, Cañadas-De la Fuente GA. Burnout and its relationship with personality factors in oncology nurses. Eur J Oncol Nurs. 2017; 30: 91-96.

16. Jaworowska A. Kwestionariusz Wypalenia Zawodowego LBQ M. Santinello. Polska normalizacja. (Polish normalization of LBQ The Link Burnout Questionnaire M. Santinello). Warszawa Pracownia Testów Psychologicznych PTP, 2014.

17. Mazur A, Goś A, Humeniuk E. Existential attitudes and Occupational burnout syndrome in nurses. Nursing in the 21st Century. 2016; 15(3): 5-10. doi: https://doi.org/10.1515/pielxxiw-2016-0021.

18. Pinikahana J, Happell B. Stress, burnout and job satisfaction in rural psychiatric nurses: a Victorian study. Aust J Rural Health. 2004; 12(3): $120-125$.

19. Yuguero O, Ramon Marsal J, Esquerda M, Vivanco L, Soler-González J. Association between low empathy and high burnout among primary care physicians and nurses in Lleida, Spain. Eur J General Pract. 2017; 23(1): 4-10.

20. Arman M, Hammarqvist AS, Rehnsfeldt A. Burnout as an existential deficiency - lived experiences of burnout sufferers. Scand J Caring Sci. 2011; 25: 294-302.

21. Kolthoff KL, Hickman SE. Compassion fatigue among nurses working with older adults. Geriatr Nurs. 2016; 4572 (16): 154-159.

22. Lee Y, Seomun G. Role of compassion competence among clinical nurses in professional quality of life. Int Nurs Rev. 2016; 63(3): 381-387.

23. Durkin M, Beaumont E, Hollins MCJ, Carson J. A pilot study exploring the relationship between self-compassion, self-judgment, self-kindness, compassion, professional quality of life and wellbeing among UK community nurses. Nurse Educ Today. 2016; 30(46): 109-114.

24. Duarte J, Pinto-Gouveia J. Empathy and feelings of guilt experienced by nurses: A cross-sectional study of their role in burnout and compassion fatigue symptoms. Applied Nursing Research. 2017; 35: 42-47. 
25. Taleghani F, Ashouri E, Saburi M. Empathy, Burnout, Demographic Variables and their Relationships in Oncology Nurses. Iran J Nurs Midwifery Res. 2017; 22(1): 41 -45.

26. Gandoy-Crego M, Clemente M, Mayan-Santos JM, Espinosa E. Personal Determinants of burnout in nursing staff at geriatric centers. Arch Gerontol Geriat. 2009; 48: 246-249.

27. Vander ET, Cavents C, Daneels K, et al. Job demands-resources predicting burnout and work engagement among Belgian home health care nurses: A cross-sectional study. Nurs Outlook. 2016; 4(16): 30112-30119.

28. Garrosa E, Moreno-Jimenez B, Liang Y, Gonzalez JL. The relationship between socio-demographic variables, job stressors, burnout and hardy personality in nurses: An exploratory study. Int J Nurs Stud. 2008; 45: $418-427$.
29. Kurowska K, Zuza-Witkowska A. Empatia a wypalenie zawodowe pielegniarek onkologicznych. Now Lek. 2011; 80(4): 277-282.

30. Włodarczyk D, Obacz W. Perfectionism, selected demographic and job characteristics as predictors of burnout in operating suite nurses. Med Pr. 2013; 64(6): 761-73.

31. Dębska G, Cepuch G. Professional burnout in nurses working in the primary health care. Probl Piel. 2008; 16(3): 273-279.

32. Nowrouzi B, Lightfoot N, Larivière M, Carter L, Rukholm E, Schinke R, Belanger-Gardner D. Occupational Stress Management and Burnout Interventions in Nursing and Their Implications for Healthy Work Environments: A Literature Review.See comment in PubMed Commons below Workplace Health Saf. 2015; 63(7): 308-315. 